Uni-molecular Reaction.--In the great majority of surface actions the effect of the catalyst is to simplify the reaction, lower the heat of activation, and make the change uni-molecular. The general relation becomes

$$
\frac{d x}{d t}=\frac{K(a-x)}{\mathrm{I}+\beta x}
$$

and, when $K$ and $\beta$ are independent of $x$, integrates to

$$
K=\frac{\mathrm{I}+a \beta}{t} \log _{e} \frac{a}{a-x}-\frac{\beta x}{t}, \quad . \quad \text {. }
$$

where

$$
k=\frac{\mu_{A} \tau_{A} k}{\Sigma \mu_{A} \tau_{A} a+\xi / n \Sigma \mu_{A} a} \text {, and } \beta=\frac{\Sigma m / l \mu_{B} \tau_{B}-\mu_{A} \tau_{A}}{\Sigma \mu_{A} \tau_{A} a+\xi / n \Sigma \mu^{A} a} \text {. }
$$

The form of (6) varies markedly with the values of the constants, and the majority of the forms it can assume have been experimentally verified by Hinshelwood and co-workers in their experiments on the decomposition of gases on hot wires. I have repeated the experiments on the decomposition of nitrous oxide and ammonia by platinum, and find good agreement with (6). The dehydrogenation of ethyl alcohol by copper in closed vessels also follows this equation. It is to be observed that it is now unnecessary to assume that the surface is saturated to obtain relation $(6)$.

St. John's College, Cambridge, January ${ }^{5}$.

\section{Discovery and Dialectics.}

Prof. MAsson, in NATURE of January 2, courteously dissents from the conclusions expressed in my, "Science and Scientists in the Nineteenth Century," and, thanks to the courtesy of the editor, I am allowed to reply.

My proof-sheets were revised by seven Cambridge fellows, who were kind enough to give me the benefit of their accurate knowledge in the different departments of science with which I deal. In addition to them, Sir A. E. Shipley, Sir J. J. Thomson, Sir Joseph Larmor, and Sir Oliver Lodge read through my proofs and made many helpful suggestions. The last, in his Introduction, expressly agrees with my conclusion that there are every whit as many prepossessions in science as there are in theology. The warfare between science and theology is, therefore, in no wise unique; for a similar warfare is characteristic of every form of human knowledge.

This is my main thesis, and Prof. Masson does not seriously attack it. He does, however, dissent from my conclusion that men of science do not receive new ideas with enthusiasm, suggesting that if they oppose them they are the rank and file of the scientific army. Let us take, therefore, two outstanding contributions to knowledge, the conservation of energy and the evolution of species. Joule performed not merely one experiment but many experiments, and a man of the standing of Kelvin points out that scientists like Graham or Miller objected to the results of these experiments, saying "simply he did not believe in Joule because he had nothing but hundredths of a degree to prove his case by." Mohr, Mayer, and Helmholtz shared the keen hostility Joule encountered. Gustav Magnus warned Helmholtz against undue partiality for mathematics, and the attempt to bring remote provinces of physics together by its means. Poggendorf thought that the paper of Helmholtz on the conservation of energy was not worth publishing in the Annalen. The older physicists, like Dove and Reuss, would not admit the principle of the conservation of energy. Distinguished mathematical colleagues like Eisenstein and LejeuneDirichlet seconded the opposition of Dove and Reuss.

Darwin succeeded in obtaining the qualified approval of Lyell, Hooker, and Huxley to his illuminating conception. With these three signal exceptions, it is true to say that the leading men of the world of science offered the stoutest opposition to his ideas. Sir Richard Owen was a naturalist who occupied such a foremost position in science that he has been called the British Cuvier, and he could not see his way to accept the new view. Among the opposition were W. H. Harvey, J. H. Balfour, H. Falconer, Sir E. Sabine, H. C. F. Jenkin, St. G. J. Mivart, A. Gray, L. J. R. Agassiz, J. L. A. de Quatrefages de Bréau, G. A. Brullé, F. J. Pictet, J. H. C. Fabre, Henri Milne-Edwards, O. Volger, R. A. von Kölliker, and K. E. von Baer. The bulk of the criticisms given in my book appeared almost immediately after the publication of the " Origin of Species," and I do not think that I have given any criticism of later date than the year 1864 , within five years of its appearance. These critics leave on the mind of the candid reader the impression Huxley took the trouble to record in I887: "There is not the slightest doubt that, if a General Council of the Church scientific had been held at that time (c. I86o), we should have been condemned by an overwhelming majority." In 1885 he wrote: "It is curious now to remember how largely at first, the (scientific) objectors predominated."

Broughton Rectory,

Robert H. Murray. Huntingdon.

Dr. MUrRay's reply to my review makes me feel, like the Elephant's Child, " a little warm, but not at all astonished." For I have not been taken literally, and I wished to be. Nor, I think, has Sir Oliver Lodge; for, whatever opinion the words of his "Introduction" may cover, in them he most certainly does not " expressly agree" that science is as full of prepossessions as is theology ; he presents Dr. Murray's conclusion and its consequence, but his personal verdict on the question of equality is withheld. So far am I from dissenting from Dr. Murray's statement that new ideas are not enthusiastically received in the scientific world, that I was at pains to emphasise this fact, and went further by asserting that this coldness plays an indispensable part in the method of science by counteracting hasty belief. That Dr. Murray neglects the fundamental value of decent scepticism is my main quarrel with him. Please, I did not suggest that only the rank and file pooh-pooh new ideas! I expressly included every one. In doing so, I propounded an idea, and Dr. Murray has unkindly blighted it by neglect; I said, "Moreover, no man of science, not even the greatest, has more than a short period in his life during which he is so free from human vanities that his discoveries are faultless and his opinions just." Dr. Murray implies that I called Joule's work " one experiment"; I said " one research."

I shall not, I hope, be thought guilty of impatience if, for the sake of saving space, I close by referring any one who wishes to concern themselves in these matters $(a)$ to the literal sense of my article of January 2, $(b)$ to Sir Oliver Lodge's Introduction to (c) Dr. Murray's well-founded facts about men of science, and (d) to Dr. Murray's natural, but-I am sorry!-fallacious inferences about science.

Irvine Masson. 